\title{
HispanismeS
}

Revue de la Société des Hispanistes Français

18 | 2021

Murs, barrières, obstacles dans les mondes

hispaniques II

\section{Los muros del terror etarra en testimonios y ficciones}

Les murs de la terreur de l'ETA en témoignages et fictions

The walls of ETA terror in testimonies and fictions

\section{María Dolores Alonso Rey}

\section{OpenEdition}

Journals

Edición electrónica

URL: https://journals.openedition.org/hispanismes/14120

DOI: 10.4000/hispanismes. 14120

ISSN: 2270-0765

Editor

Société des Hispanistes Français

\section{Referencia electrónica}

María Dolores Alonso Rey, «Los muros del terror etarra en testimonios y ficciones », Hispanismes [En línea], 18 | 2021, Publicado el 31 diciembre 2021, consultado el 30 enero 2022. URL: http:// journals.openedition.org/hispanismes/14120 ; DOI: https://doi.org/10.4000/hispanismes.14120

Este documento fue generado automáticamente el 30 enero 2022.

\section{cc) $(1) \odot$}

Les contenus de cette revue sont mis à disposition selon les termes de la Licence Creative Commons Attribution - Pas d'Utilisation Commerciale - Pas de Modification 4.0 International. 


\title{
Los muros del terror etarra en testimonios y ficciones
}

\author{
Les murs de la terreur de l'ETA en témoignages et fictions \\ The walls of ETA terror in testimonies and fictions
}

María Dolores Alonso Rey

Las paredes urbanas se convierten en soporte de escritura y por ello en espacio de comunicación social. Según Barthes, «personne n’a écrit sur le mur, et tout le monde le lit. C'est pourquoi, emblématiquement, le mur est l'espace topique de l'écriture moderne»1. El grafiti y el tag se suelen abordar desde el punto de vista de la estética o de la semiología. A las pintadas de tipo político se les concede algunas páginas, en presentaciones cronológicas, cuando se aborda 1968 con el mayo francés, la brigada Ramona Parra chilena o el conflicto norirlandés ${ }^{2}$, pero están ausentes en trabajos que tratan de los muros y sus funciones ${ }^{3}$. Como los muros exteriores son soporte de «mensajes políticos que testimonian sobre una batalla simbólica (también material) profundamente consolidada $»^{4}$, las ciencias sociales comienzan a prestar atención a pintadas y murales de grupos nacionalistas y terroristas de diferentes zonas europeas, aunque sean considerados «objetos menores de estudio». Tales producciones se clasifican como mensajes de mitificación de militantes, de marcas territoriales, de exaltación de referencias históricas, de apoyo a presos, de amenaza e intimidación, de propaganda partidista y de hermanamiento con otros grupos ideológicos ${ }^{6}$.

2 De la ingente cantidad de pintadas que han poblado los muros del País Vasco han dado cuenta los autores de ficción y de obras testimoniales ${ }^{7}$. Dicha presencia nos interpela en textos como los de Ulayar ${ }^{8}$ y Pagazaurtundúa ${ }^{9} \mathrm{o}$ en ficciones como Patria ${ }^{10}$ y Los Gondra $^{11}$. ¿Qué lugar ocupan los carteles y pintadas en los relatos testimoniales y de ficción sobre el terrorismo? ¿Cómo se representan en el texto escrito? ¿Qué función se les da? Para responder a estos interrogantes nos centraremos primero en los carteles que mitifican a los terroristas, después en las pintadas de amenaza y por último en la eliminación de pintadas y carteles. 


\section{Carteles: mitificación del terrorista}

3 Las numerosas alusiones a pintadas, fotos y carteles en Patria reflejan en la ficción la saturación iconográfica de las paredes vascas. Los muros de espacios exteriores e interiores, tanto públicos como privados se describen como tapizados de carteles y fotos. En tabernas y habitaciones, los carteles cargan de significado político el espacio al tiempo que refuerzan el sentimiento de pertenencia e identidad. La enumeración de los componentes gráficos reproduce el abigarramiento espacial y visual: «Arantxa lanzó una mirada a las paredes cubiertas de carteles: amnistía, independentzia, ETA, fotos de militantes del pueblo encarcelados, carteles electorales de Herri Batasuna» ${ }^{12}$. Otras veces, se insiste en el frenesí de la acción tanto como en la producción: «con otros estudiantes desplegaban pancartas, pegaban carteles, repartían folletos o hacían pintadas en las paredes de la facultad $»^{13}$.

4 Textos e imágenes se dan a ver cuando se mitifica al terrorista. La descripción de las fotografías pone de relieve la manipulación emocional que pretenden. Como el objeto es percibido siempre por un personaje, el lector accede tanto a la percepción física de éste como a su percepción intelectual, condicionada por su posicionamiento ante el terrorismo. Se pasa de la percepción al análisis, del ojo al pensamiento:

JOXE MARI ASKATU. Fue lo primero que golpeó la atención de Gorka nada más bajarse del autobús. Una pancarta de grandes dimensiones extendida entre dos fachadas. Y luego, a cada trecho, carteles con la foto de su hermano y la misma exigencia de liberación. Así se manipula a un hombre y se fabrica un héroe ${ }^{14}$.

Gorka, reacio al terrorismo, pero a la vez colaborador, percibe y analiza los mensajes sobre la detención de su hermano. A la percepción le siguen la emoción, expresada con la elección semántica («golpea la atención») y la racionalización. Primero presta atención a la cantidad y la dimensión de los soportes: la tipografía en mayúsculas reproduce el gigantismo del mensaje en vasco que se impone a la lectura. Después, se centra en la función de textos e imágenes como herramientas de instrumentalización del terrorista.

6 En el entorno terrorista, exhibir la juventud del preso en el espacio público, sea cual sea su edad, es una constante en sus actos cuasi litúrgicos. Se trata de una estrategia comunicativa y propagandística mediante la cual se escenifica un combate inconcluso intergeneracional por una comunidad natural etnolingüística trascendente dotada de sus mitos, su historia y su territorio ${ }^{15}$. En el homenaje a un ex-preso, el narrador subraya la incongruencia iconográfica que se plantea entre el homenajeado, un hombre envejecido, y la imagen de juventud que se exalta. Describe la imagen escamoteándola ya que la utiliza como mero punto de comparación respecto de su referente actual: «una foto en blanco y negro del homenajeado cuando era más joven, cuando tenía más pelo, menos barriga y menos papo» ${ }^{16}$. En la descripción de una manifestación de familiares de presos, por un lado, está la descripción objetiva del material gráfico: «Cada cual sostenía entre las manos un palo largo. Lo coronaba un cartel. El cartel mostraba la foto de un militante de ETA encarcelado y, debajo, su nombre» ${ }^{17}$. Por otro lado, el análisis iconográfico del narrador y de los personajes que señalan la idealización de los fotografiados: «Los retratados, jóvenes sin excepción» ${ }^{18}$. Las víctimas desmitifican el acto empleando la palabra en su justeza semántica y judicial: asesinos. Al calificar la manifestación de "procesión de los asesinos»" ${ }^{19}$, señalan la esencia 
religiosa tanto de la ideología nacionalista, como de sus rituales y liturgias sociales ${ }^{20}$ con las que pretenden santificar a los presos.

7 En la ficción, la écfrasis y el perspectivismo se alían para dar cuenta de la propaganda nacionalista y terrorista y para desactivar sus mecanismos de mitificación. En las obras testimoniales, este tipo de producciones orientadas a la sublimación de los terroristas está ausente, como es lógico. Se da cabida únicamente a las pintadas intimidatorias.

\section{Pintadas de intimidación y amenaza}

8 En las obras testimoniales, las pintadas están siempre en relación con la memoria. Se transcriben entre comillas y en minúscula. Maite Pagaza dedica un capítulo a una pintada sólo comprensible para los habitantes de su pueblo, discípulos de una profesora de vasco. La frase de la profesora hecha pintada le da pie para rememorar la historia de las ikastolas desde los años 70 y para descalificar el género:

Acordarse de Maritxu para censurar al recién elegido alcalde fue un rasgo de ingenio de los pocos que se han podido leer en las decenas de miles de pintadas que existieron y existen a lo largo y ancho de nuestra geografía. [...] género literario [...] tontuno y simple en los conceptos que se manejan y poco sorprendente en la forma ${ }^{21}$.

9 En Morir para contarlo, Salvador Ulayar, reproduce las amenazas escritas y orales, públicas y privadas, destinadas a su familia tras el asesinato de su padre. Cuando se refiere a ellas, utiliza el verbo "escupir» uniendo dos de sus acepciones - arrojar con violencia y hacer escarnio a alguien-: «pintadas amenazadoras [...] que escupían: "Ulayar, terminarás como tu padre" " ${ }^{22}$. Como su hermano maestro, él también fue destinatario de graffitis. Su discurso es en el fondo un análisis pragmático ${ }^{23}$ de los actos de habla que son las pintadas. Tras señalar el material y la ubicación, proporciona el enunciado, el acto locutivo: «una pintada de rotulador en la pared de clase, junto a mi pupitre: "ETA más metralleta" ${ }^{24}$. La víctima obvia su dimensión ilocutiva, la intención del mensaje: el emisor, un preadolescente, ordena a la banda terrorista que asesine también a su compañero de clase, testigo del asesinato de su padre, por ser su hijo. No analiza cómo el mal, fruto del mimetismo, permea todas las instituciones y segmentos sociológicos. No valora el alcance moral del contenido, solo le interesa poner de relieve su dimensión perlocutiva, esto es, el efecto provocado en el destinatario: «Qué manera de ofender en lo más profundo, de insultarme de manera tan monstruosa como gratuita» ${ }^{25}$.

Las pintadas intimidatorias son actos de habla de tipo asertivo, directivo, expresivo y declarativo. Son asertivos porque dicen la realidad: una parte de los ciudadanos debe ser eliminada. El emisor expresa sus sentimientos de odio y rechazo en mensajes que son directivos en la medida en que la amenaza busca modificar la conducta y la salud mental del destinatario. Son declarativos ya que modifican la realidad, en diferente grado, pues el señalamiento público tiene como finalidad que los conciudadanos del destinatario del mensaje lo excluyan socialmente, como mínimo.

11 ¿Cómo narrar una amenaza de muerte oral o escrita? Tanto Ulayar como el dramaturgo Borja Ortiz de Gondra se han enfrentado a esta cuestión de modo similar. A Ulayar le interesa sobre todo reflexionar sobre el mal. En lugar de ocuparse de la forma de la amenaza o del efecto de la acción, reconstruye mentalmente su génesis. Segmenta la 
acción cronológicamente y aísla cada uno de los gestos que se han ido encadenando sin que el arrepentimiento los interrumpa:

Alguien quiso darse el placer de llamar a la casa del asesinado [...] Se ocupó bien conscientemente de buscar en la guía telefónica y marcar uno a uno los números; de esperar a que se estableciera la conexión, sonaran los timbrazos y, finalmente, mi madre descolgara ${ }^{26}$.

12 Tal fragmentación le conduce a poner el foco en el instante que separa el bien del mal. Por ello puede presentar como idéntica la naturaleza del daño del que sus padres fueron objeto :

[...] el mínimo intervalo de tiempo transcurrido entre el «dígame» [...]de Rosa y la culminación del despreciable propósito [...] marca la última línea fronteriza entre la civilización y el fanatismo deshumanizador de los totalitarios. Tal inhumana determinación tiene la misma raíz que la que impulsó al asesino de Jesús Ulayar ${ }^{27}$.

Borja Ortiz de Gondra dramatiza ese instante fronterizo del que habla Ulayar: «el último segundo antes de que se produzca lo que no tendría remedio» ${ }^{28}$. Los Gondra y Los otros Gondra están concebidas como una autoficción ${ }^{29}$ metafictiva ${ }^{30}$. El dramaturgo protagonista, cuya identidad coincide con la del autor y actor que lo interpreta, escribe sobre su familia, tras el fin del terrorismo y la muerte de su hermano. La autoficción metafictiva da cuenta de la génesis de una obra gracias a la presencia de diferentes materiales textuales, o ante texto ${ }^{31}$. Las diferentes versiones sobre una misma situación ofrecen no sólo perspectivismo sino la reiteración de los hechos que, en el mundo civil, intentan olvidarse. En LOG, dos escenas, que giran en torno al arrepentimiento en el momento de amenazar de muerte mediante pintada, se ubican, en el frontón, en 1985, fecha en la que su prima extorsionaba ${ }^{32}$ a su hermano. Cada una de ellas presenta el arrepentimiento en dos momentos diferentes. En Tal vez la primera escena, la prima no llega a pintar ni la diana ni las iniciales del extorsionado. Confía en que el amago de la pintada y su discurso surtan el efecto intimidatorio deseado para doblegar la voluntad de su primo. La extorsionadora se encuentra en el límite de la acción moral. Dicha posición se expresa mediante la disonancia que existe entre su discurso y sus actos. A pesar de la agresividad de sus palabras, su lenguaje corporal adolece de firmeza: «el espray tiembla en la mano de su prima» $»^{33}$. El extorsionado se impone con su fuerza para impedir que la amenaza adquiera dimensión pública: «La mano va a trazar el gesto, pero Juan Manuel la detiene en el último momento» ${ }^{34}$. En cambio, en ¿ $Y$ si fuera esta otra la primera escena?, el umbral moral está a punto de traspasarse: «La diana está a medio pintar ${ }^{35}$. Se cruza cuando el extorsionado, que ha intentado borrarla sin éxito, se niega a abandonar su tierra, como se le ordena, y encoleriza a su prima quien «completa la diana que estaba a medio pintar sobre el frontón. Luego, con rabia y con furia, traza sobre ella las iniciales de Juan Manuel: "J. M. O. G." "» ${ }^{36}$. El arrepentimiento inmediato, victoria de la razón sobre la pasión, revierte lo todavía no irreversible: «Después, Ainhoa tacha violentamente con el espray las iniciales. Pero la diana sigue siendo claramente reconocible» ${ }^{37}$.

14 En Los Gondra, la diana con las iniciales de la víctima sirve para llevar a escena la extorsión, la amenaza y el arrepentimiento en la frontera entre el bien y el mal. En la ficción narrativa, en Patria, la diana es el signo que precede al asesinato o lo solicita: «días antes [del asesinato] había aparecido en el muro del quiosco de música su nombre dentro de una diana $\aleph^{38}$. Las pintadas, por su parte funcionan como avisos o eslabones en la cadena de la amenaza: «De sorpresa no le ha podido pillar. Ya se lo venían anunciando con pintadas» ${ }^{39}$. En la diégesis, las pintadas funcionan como marcadores 
temporales. Son el eje sobre el cual se ordenan los acontecimientos: «Al Txato, por entonces, aún no le habían hecho las pintadas, [...]; pero ya había recibido más de una carta de la organización. Nerea no lo sabía. Xabier tampoco» ${ }^{40}$. Marcan, así mismo, la temporalidad del terror en tres ámbitos: la ocupación del espacio mediante mensajes, la respuesta social a los mismos y su impacto psicológico en la víctima.

Los hechos pueden disponerse mediante una gradación cronológica de agresiones que culminan en asesinato, como sucede en la narración de la historia del concejal no nacionalista Manuel Zamarreño, asesinado en $1998^{41}$, personaje real introducido en la diégesis ${ }^{42}$. Los elementos metafictivos difuminan las fronteras entre realidad y ficción para acentuar la verosimilitud del texto ficticio de modo que éste se perciba como documento auténtico ${ }^{43}$ :

Manolo llevaba pocos días en el cargo [...], le quemaron el coche. Lo insultaban, le hacían carteladas vejatorias usando su fotografía y le pintaron el nombre dentro de una diana. [...] se quedó una semana, [...] hasta su hora fatal aquel jueves de junio ${ }^{44}$.

Esta disposición instruye al lector en el modus operandi terrorista y, por contraste, le ayuda a reubicar cronológicamente los acontecimientos que incumben a la víctima ficticia. En Enemigo del pueblo, cuento de Los peces de la amargura, se remontaba la cronología desde el suicidio de la víctima hasta el hecho que lo causaba: una falsa acusación de delación. En Patria, los jalones de la amenaza se ofrecen dispersos al lector y en una cronología invertida, dado que la novela presenta una estructura temporal laberíntica con gran cantidad de analepsis, repeticiones y perspectivas en las 125 secuencias que la forman sin disposición lógica aparente ${ }^{45}$. Por lo que respecta a la víctima mortal, se parte del asesinato y se remonta hasta la extorsión, haciendo hincapié en los eslabones de la amenaza: las pintadas.

El desenlace se enuncia desde el principio: «una de las últimas [pintadas], la de la diana encima del nombre del difunto, que fue ponerla y a los pocos días, adiós ${ }^{46}$. En segundo lugar se rememora la amenaza explícita de asesinato sugerido mediante onomatopeya: «una mañana apareció una de tantas pintadas: TXATO ENTZUN PIM PAM PUM» ${ }^{47}$. Posteriormente se avanza la pintada con la falsa acusación que presagia y justifica el asesinato: «Una de tantas [pintadas]: TXATO TXIBATO. Por la rima, supongo, pero el caso es difamar y meter miedo» ${ }^{48}$. Por último se conoce la primera pintada con la que se inicia el acoso público que complementa y potencia el chantaje sufrido en privado, hecho que pasa desapercibido para las víctimas: «A ninguno de los dos se le ocurrió vincular la pintada con las cartas de extorsión ${ }^{49}$. Esta primera pintada queda circunscrita al ámbito laboral, por su ubicación -muro interior de la fábrica-, público receptor y naturaleza del mensaje: «letras grandes y torcidas, trazadas con pintura de espray: CHATO OPRESOR ${ }^{50}$. Estos jalones que conducen al asesinato se reproducen con mayúsculas. Mediante la enumeración de los textos en letras minúsculas se da cuenta de la profusión y extensión territorial de pintadas más banales: «Chivato, opresor, traidor. Le habían escrito de todo, en euskera y en castellano, en su calle, en las adyacentes, en la plaza» ${ }^{51}$.

El lector no solo debe ordenar cronológicamente las fases del acoso sino valorar su ubicación. La primera pintada, la más alejada del domicilio de la víctima, es la que ocupa el último lugar en la diégesis. De todo ello ha de deducir que existe una correlación espacio-temporal: a mayor proximidad de las pintadas al domicilio de la víctima, menor es su tiempo de vida. 
19 En la novela de Raúl Guerra Garrido La Carta (1990), el protagonista, un empresario extorsionado, vive la presión del chantaje íntimamente, en solitario, primero, y después en familia. Por ello son importantes los pasajes en los que siente el miedo con sus manifestaciones fisiológicas y psicológicas ${ }^{52}$. En cambio, en Patria interesa ante todo mostrar el proceso de muerte civil al que se somete al extorsionado antes de asesinarlo. En una sociedad en la que la nación se presenta como trascendencia, la exclusión llega a la eliminación física ya que se discriminan «dos categorías de personas separadas por un muro infranqueable que divide a los seres en contacto con la verdad sagrada de los no iniciados quienes [...] pertenecen al ámbito de lo profano y de la herejía» ${ }^{53}$.

Las pintadas son el instrumento que desencadena y pauta la muerte civil como bien enuncia uno de los terroristas de la ficción: «Patxi llevaba tiempo preparando el terreno con una campaña de pintadas y acoso, y que: -Ahora mismo no hay dios que mueva un dedo por el empresario» ${ }^{54}$. Esa violencia de todos contra la víctima se extiende por contagio mimético ${ }^{55}$ hasta alcanzar la unanimidad en el mal: «No eran una pintada ni dos; eran doce, quince, veinte, y seguían calle abajo y calle arriba. Allí había habido muchas manos. Esto es cosa gorda y planeada ${ }^{56}$. La reacción buscada, el abandono social de la víctima, es igualmente de naturaleza mimética: «De la noche a la mañana mucha gente del pueblo empezó a negarles el saludo. [...] Hasta la mirada les negaban $»^{57}$. De ahí que la ausencia de acciones efectivas en defensa del inocente se equipare a una agresión: «Todavía quedan en las calles del pueblo pintadas contra él. ¿Tú crees que a los vecinos se les ocurre borrarlas? $»^{58}$. A medida que las pintadas ganan en extensión geográfica y se aproximan a la casa de la víctima, el número de interacciones sociales desciende. El aislamiento que se inicia en los círculos sociales más alejados acaba afectando a las amistades más cercanas: «Nada. Decirte que lo siento, que no te puedo saludar porque me traería problemas. Pero si te veo por la calle, que sepas que te estoy saludando con el pensamiento» ${ }^{59}$. Con la vergonzante participación en el mal del personaje de Joxian, con el cálculo de las ventajas que le reporta la adhesión a la violencia mimética, se evidencia el mecanismo de la espiral del silencio. Para Noelle-Neumann ${ }^{60}$, los individuos que se sienten en minoría silencian sus opiniones y modifican su comportamiento en la esfera pública por miedo a quedarse aislados socialmente ${ }^{61}$. Cuando el contexto social o espacial cambia, se debilita la presión ejercida por el grupo de modo que el mimetismo violento hacia la víctima desparece por inoperante: «Y les ocurría al Txato y a ella que algunos conocidos que les negaban el saludo en el pueblo, les decían hola e incluso se paraban a hablar un rato, qué bonito día, ¿eh?, con ellos en San Sebastián» ${ }^{62}$.

21 El texto escrito de la pintada actúa como estímulo que genera una respuesta social unánime: silencio, negación de la palabra. Protege a quien no desea ser asimilado a la víctima y le niega a esta última tanto su lugar en el seno de la comunidad como su condición humana. Que el silencio es una agresión que hace de quien lo practica un eslabón más en la cadena terrorista bien se ve en la novela Años lentos de Fernando Aramburu. Una novela del novelar en la que un escritor, homónimo del autor real, arrepentido de haberse dejado llevar por los rumores en su adolescencia, proyecta escribir una novela para pedir perdón públicamente por no haber saludado a su vecino ya fallecido.

22 Las pintadas intimidatorias son pues un instrumento que permite a las organizaciones terroristas adueñarse psicológicamente de la población. Provocan un clima de miedo e inseguridad propicio a la violencia mimética con la que se anula al disidente. Procuran 
además a las organizaciones terroristas la asistencia material necesaria para su financiación y logística63.

\section{Arrancar carteles y borrar pintadas}

La acción opuesta a pegar carteles y escribir pintadas es arrancarlos y borrarlas. Durante la etapa terrorista, son comportamientos defensivos. En Patria, A Gorka le piden deshacerse de todo material político de la habitación de su hermano ante un inminente registro policial: «O sea: pósters, propaganda, algún Zutabe. Ah, pues sí, había bastante. Que lo rompiera todo echando leches» ${ }^{64}$. Para los contrarios al terrorismo, borrar una pintada es un acto cívico, de justicia, coraje y dignidad personal: «Una noche bajó a la calle con un bote de pintura para borrar una pintada, ETA HERRIA ZUREKIN, que había aparecido por la tarde junto al portal. Y Arantxa trató de disuadirlo, mira que te vas a meter en un lío, pero él bajó» ${ }^{65}$.

En cambio, descolgar una foto-cartel es un acto positivo en los homenajes a los presos liberados. Retirar la foto de la errikotaberna es un ritual que simboliza la libertad y la reintegración al grupo: «Escoltado por un centenar de chavales, Karburo fue conducido a la Arrano Taberna. Entre aplausos y goras a ETA descolgó de la pared su foto de preso. Después pasó al comedor...» ${ }^{66}$

Ante las pintadas, la víctima pone en marcha diferentes estrategias de respuesta que van marcando igualmente una temporalidad que debe restablecer el lector: desde la fortaleza psicológica ante la amenaza hasta la muerte civil. Txato comienza haciéndose el fuerte. Su clarividencia le lleva a ignorar las amenazas y el acoso: «los canallas que llaman para insultar y amenazar, y los que hacen las pintadas, me traen sin cuidado. [...] ¿Qué buscan? Pues tenerme acojonado en casa o que me vaya a vivir a otra parte. No me dan ningún miedo» ${ }^{67}$. Posteriormente, en el espacio público, cual Sísifo, se defiende utilizando las mismas armas: la pintura. Ocultar las pintadas se convierte en una tarea inconclusa e inabarcable:

Al principio borraba a brochazos las pintadas que le hacían en la puerta metálica del garaje. Se había agenciado con dicho fin un balde de pintura blanca; pero era inútil. Al día siguiente se las volvían a hacer. Txato faxista, opresor, ETA mátalo68.

En la obra dramática Los Gondra, la indefensión del extorsionado se expresa mediante un borrado fallido para el que carece de materiales adecuados. Solo se evidencia el gesto defensivo desesperado: «De pronto, sin mediar palabra, Juan Manuel intenta desesperadamente borrar la diana con su pañuelo ensangrentado, pero es un empeño inútil» ${ }^{69}$.

La tercera estrategia, en Patria, es evitar la lectura y la presencia de los textos: «Se acostumbró a no mirar las pintadas» ${ }^{70}$. La cuarta, nunca aceptada, es el destierro: «Deberíais vivir la ama y tú en otro sitio, [...] ¿Que hacen pintadas en las paredes? Pues que las pinten. Si tú no estás allí para verlas... » ${ }^{71}$ Tras la resistencia fallida, se impone la claudicación ante la extorsión por el procedimiento habitual ${ }^{72}$ : «Por medio de un enlace pedí un encuentro en Francia. La idea era explicarles mi situación financiera, [...] y pedirles una prórroga o que me dejen pagar a plazos» $»^{73}$. La última estrategia corre a cargo de la familia: evitar la profanación de la tumba. Del mismo modo que se estableció un paralelismo en el asesinato entre Txato y el concejal Zamarreño, la suerte post mortem de la víctima de ficción se liga a la de otra víctima real del terrorismo ${ }^{74}$, 
teniente alcalde de San Sebastián, que se introduce en la diégesis para reforzar el realismo de la ficción:

Lleva muchos años esperando el traslado al cementerio del pueblo. No lo hemos hecho todavía para evitar que le pase lo que a Gregorio Ordóñez, que está enterrado más abajo. [...] Hubo un tiempo en que le hacían pintadas ofensivas en la tumba. Igual lo has leído en los periódicos. Los abertzales no dais tregua ni a los muertos ${ }^{75}$.

Con el fin del terrorismo, las pintadas adquieren en la ficción una nueva dimensión y funcionalidad. El borrado de pintadas marca una nueva temporalidad: la del fin del terrorismo. En ella, junto al nuevo relato ${ }^{76}$ de los afines al terror, surge un nuevo espacio social en el que la reconciliación podría ser posible, como ocurre al final de la novela Patria. La autoridad municipal retoma el poder y competencias en el espacio urbano borrando pintadas:

fue hacia el frontón, años antes pintarrajeado de lemas a favor de ETA y símbolos de la izquierda abertzale, verde impoluto desde que no se perpetran atentados y el Ayuntamiento mandó pintar las paredes, porque hay que pasar página y mirar al futuro y que no haya vencedores ni vencidos ${ }^{77}$.

Las pintadas se convierten en huellas, en rastros de un pasado que hay que eliminar. El borrado de pintadas, signo material del advenimiento de un tiempo nuevo sin atentados mortales, inquieta tanto a las víctimas como a los afines a los terroristas. Para las primeras, la limpieza industrial de las fachadas se acompaña del temor al olvido y a persecuciones de nuevo tipo: «Nuestra memoria no se borra con agua a presión. Y ya verás cómo nos echan en cara a las víctimas que nos negamos a mirar hacia el futuro. Dirán que buscamos venganza $»^{78}$. Para los afines al terrorismo, la falta de pintadas marca la desposesión del espacio público del que eran dueños: «El pueblo ya no es lo que era. Ahora no ves pintadas ni carteles como antes. Está aquello un poco muerto ${ }^{79}$. Si la eliminación de las pintadas genera un sentimiento de extrañeza, su presencia se convierte, en Los Gondra, igualmente en un signo inquietante, el de un terror imperecedero, que sobrevive a la víctima de la extorsión: «NATALIA.- ¿No has visto el frontón, cuando hemos salido de la iglesia? Allí siguen las pintadas. Será un tiempo nuevo, pero nadie las ha borrado» ${ }^{80}$. Independientemente de su presencia o ausencia en las paredes urbanas, lo que preocupa a la víctima es el valor que se le atribuirá en la narración del pasado. La pintada y la diana son signos con significado pleno solo para las generaciones que han vivido bajo la amenaza terrorista, pero se convierte en signo vacío de sentido para las nuevas generaciones. Vaciar el signo de significado supone escamotear la transmisión de la memoria y la significación moral del crimen político: «JUAN MANUEL: ¿Tú sabes lo que era el impuesto revolucionario? ¿Lo que te ocurría si no pagabas? ¿Qué significaba una diana en el frontón? [...] - ¡Si ellos no saben, todo aquello no sirvió para nada! $»^{81}$. Escamotear el deber de memoria supone escamotear el núcleo de la memoria, esto es el proyecto totalitario de ETA, un proyecto que «niega radicalmente las conformaciones jurídicas que son los estados francés y español [...], basado en una compresión total de la sociedad vasca [...] en la que no hay lugar para diferencias internas» ${ }^{82}$.

En la realidad, tras el cese de la actividad sangrienta, las pintadas han seguido siendo un instrumento eficaz para el amedrantamiento social de las víctimas. En el libro testimonial Morir para contarlo, se cuenta la ofensa post mortem infligida a la familia Ulayar que huye de la imagen de víctimas que, como Sísifo, borran mecánicamente pintadas injuriosas para defender la memoria del asesinado. La restauración de la fachada familiar se convirtió en un gesto cívico y político en el que los medios también 
eran el mensaje: «la pintura y el rodillo de la libertad» ${ }^{83}$. En 2004, para conmemorar el vigésimo quinto aniversario del asesinato de Jesús Ulayar, la fachada de su casa y lugar del crimen se pintó de azul con manos blancas, símbolo contra el terrorismo y a favor de las víctimas ${ }^{84}$. En 2013, treinta y cuatro años después del asesinato y extinto ya el terrorismo, los proetarras mancillaron el símbolo y justificaron el crimen de 1979 con una pintada: «Gora ETA (M) eta kitto». El hijo del asesinado la traduce tanto textual («Arriba ETA militar y punto») como política y simbólicamente: «"jódete, Jesús, que bien matado estás y en la pared de tu casa lo venimos a escribir!" "»" El 14/9/2013 familia y amigos restauraron la fachada azul con manos blancas «A plena luz del día, como los hijos de la luz, de la libertad ${ }^{86}$. Salvador Ulayar presenta la restauración como un acto de protesta cívica ante el final negociado de la banda y el relato que de él se hace y se impone:

era una expresión de ciudadanía española libre: alzar la voz frente al cambalache con los totalitarios que nos quieren empujar [...] hacia la idea de que, calladas las pistolas, aquí no pasa nada porque «la ETA buena» siga en el escaño, carcajeándose de nuestros muertos y ensalzando a los terroristas ${ }^{87}$.

Así pues, tanto las obras de ficción como las testimoniales tienen como objetivo, dentro del ejercicio de la memoria, la recta comprensión de los signos y de su alcance moral en un tiempo en el que el terrorismo ha desaparecido, aunque no sus objetivos políticos ni la ideología etnonacionalista que lo sustentó.

\section{Conclusión}

Las pintadas, que no han suscitado demasiados estudios por sí mismas, tienen cabida en textos de tipo memorial y de ficción, narrativos y dramáticos. A pesar de su heterogeneidad, nuestro corpus comparte el objetivo último de dar testimonio de la violencia terrorista etarra para transmitir una memoria verídica que permita realizar el duelo. En los libros de memorias, las pintadas son materia para analizar el mal: su génesis, su sociología y sus implicaciones éticas y políticas. En la ficción dramática, las pintadas y dianas, realizadas ante la víctima, muestran, en la polis, el conflicto intestino cíclico entre víctima y verdugo de la misma familia. La repetición de las escenas ante las pintadas satura la memoria del espectador o del lector de modo que el mensaje contrasta con el relato que desde el poder político se publicita. En cambio, en la novela, se utilizan como elementos marcadores de la temporalidad en la diégesis. Por un lado, señalan el antes y el después del terrorismo con crímenes de sangre y, por otro, presentan los jalones que acompasan la muerte civil y física de la víctima.

\section{BIBLIOGRAFÍA}

María ALONSO REY, «La lógica del terrorismo: Del terror al horror en La carta de Raúl Guerra Garrido» [on-line], Tonos Digital, Revista electrónica de estudios filológicos, ‥ 27 (Enero 2015) 
[consultado el 22/02/21] <URL: http://www.tonosdigital.com/ojs/index.php/tonos/article/view/ 1209>

Fernando ARAMBURU, «Patria en el taller», Revista Grande Place, n. ${ }^{\circ}$ 7, 2017, p. 181-187.

Fernando Aramburu, Patria, Barcelona, Tusquets, 2016.

Joseba ARREGI ARANBURU, El terror de ETA. La narrativa de las víctimas, Madrid, Editorial Tecnos, 2015.

Roland BARTHES, Variations sur l'écriture, Paris, Seuil, 1994.

Sergio BLANCo, Autoficción. Una ingeniería del yo, Madrid, Punto de vista editores, 2018.

Mikel BUESA, ETA, S.A., El dinero que mueve el terrorismo y los costes que genera, Barcelona, Planeta, 2011.

Quétel CLAUDE, Histoire des murs. Une autre histoire des hommes, Paris, Éditions Perrin, 2017.

Xavier CRETTIEZ, Pierre PiazZA, Murs rebelles, Paris, Karthala, 2014.

Xavier CRETTIEZ, Violence et nationalisme, Paris, Odile Jacob, 2006.

Cristina CUESTA, Contra el olvido, Madrid, Edición Temas de hoy, 2000.

Florencio DOMínGUEZ, Las raíces del miedo, Madrid, Santillana Ediciones Generales, 2003.

Ana María DotRAS, La novela española de metaficción, Madrid, Ediciones Júcar ,1994.

El País (2017), «Rajoy elogia la "ficción real” de 'Patria' en la entrega del premio Umbral»[online], Madrid. (disponible el 10-5-2017) [consulté le 18/2/21] <URL: https://elpais.com/cultura/ 2017/05/08/actualidad/1494271426_362847.html>.

El Periódico (2008) «Profanada por quinta vez la tumba del diputado Gregorio Ordóñez» (disponible el 5/06/2008) [consultado el 3/03/2021] <URL:https://www.elperiodico.com/es/ politica/20080605/profanada-quinta-vez-tumba-diputado-162089>.

María Victoria EsCANDELL VIDAL, Introducción a la pragmática, Barcelona, Anthropos, 1993.

Daniel FERRER, « Le matériel et le virtuel : du paradigme indiciaire à la logique de mondes possibles », Michel Contat et al.,(éd.) Pourquoi la critique génétique ? Méthodes, théorie, CNRS Éditions, 1998, p. 11-30.

Bernard FoNTAINE, Découvrir et comprendre le graffiti, Paris, Groupe Eyrolles, 2014.

FUNDACIÓN MIGUEL ANGEL BLANCO (2020), «La voz de las manos blancas» (disponible el 25/11/2020) [consulté 25/02/2021] <URL: https://www.fmiguelangelblanco.es/actividades/por-la-memoria/ la-voz-de-las-manos-blancas/>.

Pilar JÓDAR, «Recursos metateatrales al servicio de la autoficción teatral en siete textos del siglo XXI», G. Laín Corona et al.(éd.), Teatro, (auto)biografía y autoficción (2000-2018), Madrid, Visor libros, 2019, p. 263-277.

Aurélia KALISKY, Pour une histoire culturelle du testimonial. De la notion de "témoignage » à celle de «création testimoniale », Tesis doctoral en literatura comparada, Paris, Sorbonne Nouvelle, 2013.

Francisco J. LLERA RAMO et Rafael LEONISIO CALVO, «La estrategia del miedo: ETA y la espiral del silencio en el País Vasco», Informe del Centro Memorial de las Víctimas del Terrorismo, n. 1, 2017, p. 9-55.

Pierre MANNONI, Les logiques du terrorisme, Paris, Éditions In Press, 2004. 
Agustín MORENO FERNÁNDEZ, «Descripción y fases del mecanismo del chivo expiatorio en la teoría mimética de René Girard», Endosa: series filosóficas, n. ${ }^{\circ}$ 32, 2013, p. 191-206.

Elisabeth NOELLE-NEUMANN, The spiral of silence: public opinion, our social skin, Chicago, The University of Chicago Press, 1993.

Borja ORTIZ DE GONDRA, Los Gondra. Los Otros Gondra, Madrid, Punto de vista editores, 2019.

Maite Pagazaurtundua, Los Pagaza. Historia de una familia vasca, Madrid, Temas de Hoy, 2004.

Marta RODRÍGUEZ FOUZ, «Batallas simbólicas. La lucha por el espacio público en Euskadi», Papeles del CEIC. International Journal on Collective Identity Research, n. ${ }^{\circ}$ 2, 2010, p. 1-50.

Izaskun SÁEZ DE LA FUENTE ALDAMA, El movimiento de liberación nacional vasco, una religión de sustitución, Tesis, Universidad del País Vasco, 2001.

Salvador UlAYAR MUNDIÑANO, Morir para contarlo, s.l., Sahats Servicios Editoriales, 2014.

Ana VARELA REY, Legitimación de la violencia y espiral del silencio: el caso de ETA en el País Vasco, Tesis, Universitat de Barcelona, 2016.

\section{ANEXOS}

Glosario

Askatu: Libertad

Entzun: ¡Oye!

ETA HERRIA ZUREKIN: Eta, el pueblo está contigo

Gora: ¡Viva!

Zutabe: Nombre del boletín interno de ETA

\section{NOTAS}

1. Roland BARTHES, Variations sur l'écriture, Paris, Seuil, 1994, p. 74.

2. Bernard FonTAINE, Découvrir et comprendre le graffiti, Paris, Groupe Eyrolles, 2014, p. 64-69.

3. Claude QUÉTEL, Histoire des murs. Une autre histoire des hommes, Paris, Éditions Perrin, 2017.

4. Marta RodRíguez Fouz, «Batallas simbólicas. La lucha por el espacio público en Euskadi», Papeles del CEIC. International Journal on Collective Identity Research, $\mathrm{n}^{\circ} 2, \mathrm{p} .2$.

5. Xavier CRETTIEZ et Pierre PIAZZA, Murs rebelles, Paris, Karthala, 2014, p. 25.

6. Ibid., p. 13-15.

7. Sobre la complejidad de la noción de testimonio y de las formas testimoniales (obra testimonial, creación testimonial, literatura testimonial), Aurélia KALISKY, Pour une histoire culturelle du testimonial. De la notion de «témoignage» à celle de "création testimoniale», Tesis doctoral en literatura comparada, Paris, Sorbonne Nouvelle, 2013.

8. Salvador UlayAR Mundiñano, Morir para contarlo, s.l., Sahats Servicios Editoriales, 2014.

9. Maite Pagazaurtundua, Los Pagaza. Historia de una familia vasca, Madrid, Temas de Hoy, 2004.

10. Fernando Aramburu, Patria, Barcelona, Tusquets, 2016.

11. Borja ORTIZ DE GONDRA, Los Gondra. Los Otros Gondra, Madrid, Punto de vista editores, 2019.

12. Fernando Aramburu, Patria, op. cit., p. 208. 
13. Ibid., p. 254.

14. Ibid., p. 469.

15. Izaskun SÁEZ DE LA FUENTE ALDAMA, El movimiento de liberación nacional vasco, una religión de sustitución, Tesis, Universidad del País Vasco, 2001, p. 283.

16. Fernando ARAmBuru, Patria, op. cit., p. 187.

17. Ibid., p. 486.

18. Id.

19. Ibid., p. 487.

20. Sobre la lógica religiosa del nacionalismo y del micro nacionalismo vasco, ver Xavier CRETTIEZ, Violence et nationalisme, Paris, Odile Jacob, 2006, p. 108-113.

21. Maite Pagazaurtundua, Los Pagaza. Historia de una familia vasca, Madrid, Temas de Hoy, 2004, p. 96.

22. Salvador UlayAR MUNDIÑANO, Morir para contarlo, op. cit., p. 73.

23. María Victoria ESCANDELL VIDAL, Introducción a la pragmática, Barcelona, Anthropos, 1993, p. 67.

24. Salvador UlayAR MUNDIÑANO, Morir para contarlo, op. cit., p. 74.

25. Id.

26. Ibid., p. 73.

27. Id.

28. Borja ORTIZ DE GondRA, Los Gondra. Los Otros Gondra, op. cit., p. 171.

29. Sobre la autoficción como "pacto de mentira» con mezcla de realidad y ficción, ver Sergio BLANCO, Autoficción. Una ingeniería del yo, Madrid, Punto de vista editores, 2018.

30. Lo factual se metamorfosea en ficticio gracias al metateatro. Ver Pilar JóDAR, «Recursos metateatrales al servicio de la autoficción teatral en siete textos del siglo XXI», G. Laín Corona et al.(éd.), Teatro, (auto)biografía y autoficción (2000-2018), Madrid, Visor libros, 2019, p. 263-277.

31. Daniel FERRER, «Le matériel et le virtuel : du paradigme indiciaire à la logique de mondes possibles ", Michel Contat et al.,(éd.) Pourquoi la critique génétique? Méthodes, théorie, CNRS Éditions, 1998, p. 11-30.

32. La extorsión, mediante el envío de cartas de amenaza a empresarios, fue el método de financiación más utilizado. La banda contaba con una organización compuesta por un comité ejecutivo (Zuba), un órgano encargado de la recaudación (Gezi) y otro de los gastos (Diva). Entre los terroristas y el amenazado se encontraban los miembros del grupo de presión (Talde) y los intermediarios. Se estima que cedieron al chantaje entre 1100 y 2200 empresarios. Mikel BUESA, ETA, S.A., El dinero que mueve el terrorismo y los costes que genera, Barcelona, Planeta, 2011, p. 8-91.

33. Borja ORTIZ DE GONDRA, Los Gondra. Los Otros Gondra, op. cit., p. 173.

34. Ibid., p. 174.

35. Ibid., p. 191.

36. Ibid., p. 195.

37. Id.

38. Fernando ARAMBURU, Patria, op. cit., p. 420.

39. Ibid., p. 232.

40. Ibid., p. 256.

41. Sobre la campaña de limpieza ideológica centrada en la eliminación de políticos e intelectuales no nacionalistas, ver Florencio DomínGUEZ, Las raíces del miedo, Madrid, Santillana Ediciones Generales, 2003, p. 263-264.

42. Sobre la metaficción como interferencia entre los mundos del autor ficticio, de la historia y del lector, ver Ana María DOTRAs, La novela española de metaficción, Madrid, Ediciones Júcar ,1994, p. 25. 
43. El País (2017), «Rajoy elogia la "ficción real” de 'Patria' en la entrega del premio Umbral»[online], Madrid. (disponible el 10-5-2017) [consultado el 18/2/21] <URL: https://elpais.com/cultura/ 2017/05/08/actualidad/1494271426_362847.html>.

44. Fernando Aramburu, Patria, op. cit., p. 428.

45. Fernando ARAMBURU, «Patria en el taller», Revista Grande Place, $n^{\circ}$ 7, 2017, p. 183-184.

46. Fernando ARAMBURU, Patria, op. cit., p. 30.

47. Ibid., p. 35.

48. Ibid., p. 82.

49. Ibid., p. 157.

50. Ibid., p. 156.

51. Ibid., p. 159.

52. María Dolores ALONSO REY, «La lógica del terrorismo: Del terror al horror en La carta de Raúl Guerra Garrido» [on-line], Tonos Digital, Revista electrónica de estudios filológicos, n.․ 27 (Enero 2015) [consultado el 22/02/21] <URL: http://www.tonosdigital.com/ojs/index.php/tonos/article/view/ 1209>

53. Izaskun SÁEZ DE LA FUENTE ALDAMA, El movimiento de liberación nacional vasco, una religión de sustitución, op. cit., p. 277.

54. Fernando ARAmburu, Patria, op. cit., p. 449.

55. Agustín MORENO FERNÁNDEZ, «Descripción y fases del mecanismo del chivo expiatorio en la teoría mimética de René Girard», Endosa: series filosóficas, nº 32, 2013, p. 194.

56. Fernando ARAmburu, Patria, op. cit., p. 334.

57. Ibid., p. 82.

58. Ibid., p. 367.

59. Ibid., p. 335.

60. Elisabeth NOELLE-NEUMANN, The spiral of silence: public opinion, our social skin, Chicago, The University of Chicago Press, 1993.

61. Sobre la espiral del silencio (EDS) en el País Vasco existen varios trabajos empíricos: Ana VARELA REY, Legitimación de la violencia y espiral del silencio: el caso de ETA en el País Vasco, Tesis doctoral, Universitat de Barcelona, 2016; Francisco J. LLERA RAMO et Rafael LEONISIO CALVO, «La estrategia del mierto: ETA y la espiral del silencio en el País Vasco", Informe del Centro Memorial de las Víctimas del Terrorismo, $\mathrm{n}^{\circ} 1$ (2017), p. 9-55.

62. Fernando ARAmburu, Patria, op. cit., p. 212.

63. Pierre MANNONI, Les logiques du terrorisme, Paris, Éditons In Press, 2004, p. 95.

64. Fernando ARAmBuru, Patria, op. cit., p. 304.

65. Ibid., p. 530.

66. Ibid., p. 188.

67. Ibid., p. 416.

68. Ibid., p. 212.

69. Borja ORTIZ DE GONDRA, Los Gondra. Los Otros Gondra, op. cit., p. 194.

70. Fernando ARAmburu, Patria, op. cit., p. 212.

71. Ibid., p. 219.

72. Testimonio de un empresario sometido a la dinámica de extorsión, negociación de pagos y secuestro, ver ver Cristina CuESTA, Contra el olvido, Madrid, Edición Temas de hoy, 2000, p. 124-128. 73. Fernando ARAMBURU, Patria, op. cit., p. 218.

74. EL PERIÓDICO (2008) «Profanada por quinta vez la tumba del diputado Gregorio Ordóñez» [disponible el 5/06/2008) [consultado el 3/03/2021] <URL: https://www.elperiodico.com/es/ politica/20080605/profanada-quinta-vez-tumba-diputado-162089>

75. Fernando ARAmburu, Patria, op. cit., p. 576. 
76. El nuevo relato consiste en la reubicación de la historia del terror remontándolo a la guerra civil, en la igualación de todas las víctimas, en la exclusión de las víctimas en la cuestión del fin de ETA, en el olvido impuesto: «[...] se busca este tipo de olvido no voluntario sino inducido por todas aquellas políticas que buscan pasar página, mirar al futuro, comenzar de nuevo, reconciliar, consolidar la paz como dejar de lado la referencia a vencedores y vencidos, dejar de lado la existencia de verdugos y víctimas, dar por buena la defensa de los proyectos que legitimaron y exigieron el asesinato de los excluidos y desposeídos siempre que no conlleven el uso de la violencia», Fernando ArAmburu, Patria, op. cit., p. 543.

77. Fernando ARAmBuru, Patria, op. cit., p. 543.

78. Ibid., p. 555.

79. Ibid., p. 454.

80. Borja ORTIZ DE GONDRA, Los Gondra. Los Otros Gondra, op. cit., p. 101.

81. Ibid., p. 224.

82. Joseba ARREGI ARANBURU, El terror de ETA. La narrativa de las víctimas, Madrid, Editorial Tecnos, 2015, p. 42.

83. Salvador UlayAR MundiÑANo, Morir para contarlo, op. cit., p. 170.

84. FUNDACIÓN MIGUEL ANGEL BLANCo (2020), «La voz de las manos blancas» (disponible el 25/11/2020) [consultado el 25/02/2021] <URL: https://www.fmiguelangelblanco.es/actividades/ por-la-memoria/la-voz-de-las-manos-blancas/>.

85. Salvador UlaYAR MUNDIÑANO, Morir para contarlo, op. cit., p. 169.

86. Id.

87. Ibid., p. 170.

\section{RESÚMENES}

La nebulosa terrorista vasca hizo un amplio uso de las pintadas para apropiarse políticamente del espacio público. Las obras de ficción y los testimonios sobre el periodo terrorista muestran esta presencia abrumadora. Estudiamos el lugar que ocupan estas producciones en las obras de nuestro corpus, la función que tienen en los diferentes géneros. Analizaremos primero las producciones que mitifican al terrorista, luego las que amenazan a las víctimas y, por último, el borrado del grafiti y su significado.

La nébuleuse terroriste basque a abondamment utilisé les graffitis pour s'approprier politiquement l'espace public. Des œuvres de fiction et de témoignage sur la période terroriste montrent cette présence écrasante. Nous étudions la place qu'occupent ces productions dans les œuvres de notre corpus, la fonction qu'elles ont dans les différents genres. Nous analyserons d'abord les productions qui mythifient le terroriste, ensuite celles qui menacent les victimes, et enfin l'effacement des graffitis et son sens.

The Basque terrorist nebula made a wide use of the graffiti in order to politically appropriate the public space. Fictional and testimonial works on the terrorist period echotheir overwhelming presence. We are interested in analyzing the place that these productions occupy in the works of our corpus, the function they have in the different genres. In the first place we deal with the productions that mythologize the terrorist, secondly those that threaten the victims and lastly the rubbing out and its meaning. 
ÍNDICE

Palabras claves: Terrorismo vasco, muros, graffiti, novela, testimonios

Keywords: Basque terrorism, walls, graffiti, novel, testimonies

Mots-clés: Terrorisme basque, murs, graffiti, roman, témoignages

\section{AUTOR}

MARÍA DOLORES ALONSO REY

Université d'Angers 